\title{
Governmentality without Truth: An Essay on the Role of Foucauldian Thinking in a Post- Truth Society
}

\author{
Marek Czyżewski \\ University of Lodz, Poland
}

DOI: http://dx.doi.org/10.18778/1733-8077.17.1.4

\section{Keywords:}

Knowledge/Power;

Governmentality;

Sociology; Truth;

Post-Truth

\begin{abstract}
Considering the issue of power in Foucault will always lead to comments on the issue of knowledge and vice versa. What I suggest in this paper, however, is to look into both topics presented in the work by Foucault separately, at least to a certain extent. I believe that the evolution of these two threads in his works allows us to evaluate their suitability differently as far as their relevance to contemporary culture is concerned. Foucault's approach to the issue of power and its evolution towards so-called governmentality is evidence of how accurately he sensed the direction of changes to the Zeitgeist of Western civilizations, a fact which cannot be said about the evolution of Foucault's approach to the issue of knowledge, leaning towards the question of truth and truth-telling. The aim of this paper is to substantiate the outlined and differentiated evaluation of Foucault's oeuvre while, at the same time, highlighting the predominant features of contemporary culture. Special attention will be paid to the role of sociology in governmentality.
\end{abstract}

Marek Czyżewski is a Professor at the Institute of Sociology and Head of the Department of Research on Social Communication, University of Lodz, Poland. His main interests include: discourse analysis; public and mass communication; public opinion and democracy; hate speech; "governmentality"; intercultural and international communication; social theory (especially interpretive approaches, sociology of knowledge, and Foucault). Editor-in-chief of "Przegląd Socjologiczny"; editor of the series Biblioteka Dyskursu Publicznego.

email address: marek.czyzewski@uni.lodz.pl

\section{Governmentality without Truth}

One of the key topics that can be observed in the texts, interviews, and other utterances of Michel Foucault in various periods of his activities is the topic of the inseparable connection, or better, interpenetration between power and the mechanisms that create knowledge. In order to express this idea, Foucault applied his famous neologism: power-knowledge (pouvoir-savoir). It is worth remembering that neither the first nor 
the latter element of this hyphenated term refers to the traditional ways of understanding the individual elements that comprise it. Therefore, it is not about relations between power understood in its usual, politological, meaning, or the cognitive meaning of the term knowledge. By outlining the horizon of the poststructuralist perspective, Foucault treats both power and knowledge as dispersed, omnipresent, multifaceted, and non-linear phenomena, and the connection between them as a partial identification. Any form of power is also an imposition of certain categories designed to interpret reality, similarly, there is no knowledge that would not pose an interpretative conquest. It would be hard to overestimate the scale of the influence this idea has had on contemporary social and humanistic sciences. This is not so much of a mutual entanglement of power and knowledge as of a deep and formative (although oftentimes unnoticeable) impact of the power-knowledge amalgam on social reality.

Needless to say, when considering the notion of power in Foucault's work, it will always (in this paper also) lead to a discussion on the topic of knowledge and vice versa. What I suggest this time, however, is looking into both notions presented in the work by Foucault (power and knowledge) separately, at least to a certain extent; I believe that the evolution of these two threads in his works allows us to evaluate their suitability differently as far as their relevance to contemporary culture is concerned. In short, Foucault's approach to the topic of power and its evolution towards so-called governmentality is evidence of how accurately, not to say prophetically, he sensed the direction of changes in the Zeitgeist of Western civilizations, which cannot be said about the evolution of Foucault's approach to the topic of knowledge leaning towards the question of truth and truth-telling.
Although I initially focus on Foucault's conceptions with the intention of justifying the aforementioned assessment of his oeuvre, the main purpose of this paper is to preliminarily sketch an outline of the properties dominating contemporary Zeitgeist, while at the same time examining the extent to which Foucault's concepts can be a tool to analyze it, and to what degree they require revision and exceedance of their limitations.

\section{Governmentality and the Role of Science in Contemporary Society}

Any further analysis of the subject of power in Foucault's works requires it to be done under the following proviso. In this paper, it is my intention to refer neither to Foucault's intellectual inspirations nor to the place his concept occupies on the map of various-both classic and modern-approaches to comprehending power. I have purposely chosen a narrow perspective for my reconstruction of Foucault's thoughts in order to present-hopefully-a deeper insight into his way of thinking, since Foucault's work is so unique that its character sometimes becomes distorted due to precipitous reflection on its origins, or as a result of formulaic reviews, comparisons, and polemics. Moreover, I intend that the approach presented herein may help deepen analyses of Foucault's oeuvre, placing it in broader academic frameworks of reference. This latter argument gains importance when, as indicated hereunder, we take into account the fact that-from a Foucauldian perspective-the vast majority of contemporary economic, psychological, educational, and social sciences ought to be subject to critical analyses rather than as just a source of knowledge on reality.

In the late 70s, Foucault significantly broadened his analytics of power. Thus far, his works had mainly concerned both sovereign power (based on legally 
codified prohibitions and the system of punishment for breaching them) and disciplinary power (based on detailed orders and surveillance as a method of executing them). More recently, a new notion has appeared in the list of basic types of relations in power, that is, governmentality. Foucault's lectures delivered in the years 1977/78 and 1978/79 are of key importance here. Although they were published in French in 2004, which is 20 years after his death (the English versions were published in 2007 and 2008), the ideas included there became the inspiration for the quite numerous "studies in governmentality," at the onset of the $21^{\text {st }}$ century (see the review of the development of this research area in Bröckling, Krasmann, and Lemke 2011).

The two main interpretations of the notion of governmentality should be recalled here. Some commentators are of the opinion that we are presently experiencing the decline of sovereign and disciplinary power accompanied by the rising influence of new, indirect, and flexible mechanisms to manage society. These rely on equipping individuals and collective entities (groups, communities, firms, organizations, or countries) with a sense of agency and autonomy (e.g., Rose 1996; Bröckling 2007). In this approach, governmentality is based on an indirect way of guiding people and their behavior (allegedly on their own). In Foucault's words (2008:186), it is "the way in which one conducts the conduct of men" which is the matter of concern. Governmentality here is identified with the neo-liberal technology of "governing through freedom" (a notion coined by Nikolas Rose) that fosters innovation, activity, responsibility for one's own actions, and so-called "personal development" in the areas of entrepreneurship, the civic sphere, as well as our personal life. It is worth emphasizing that from the linear vision (wrong, in my opin- ion) of the, supposed, transition from a "sovereign society" to a "disciplinary society" and then from a "disciplinary society" to "governing through freedom," the author of the latter notion, Nikolas Rose, also distances himself. However, Gilles Deleuze (1995) - the author of numerous, otherwise valuable, commentaries devoted to Foucault's oeuvre-yields to this picture. Although Deleuze does not apply the term "governing through freedom"-it is precisely this form of power that his concept of "the society of control" refers to.

Other commentators (e.g., Dean 2010) see governmentality as a complex set of techniques of power that displaces the dominance of sovereign power through the application of various combinations of elements of sovereign and disciplinary power, as well as "the art of government." The art of government is connected to securitization-understood as stressing the importance of the safety of the population, as well as fostering ways of ensuring it by preventing the occurrence of "case, risk, danger, and crisis" (Foucault 2007:90). For this reason, three types of power relations in contemporary society coexist and interact with each other:

So, there is not a series of successive elements, the appearance of the new causing the earlier ones to disappear. There is not the legal age, the disciplinary age, and then the age of security...In reality, you have a series of complex edifices, in which, of course, the techniques themselves change and are perfected, or anyway become more complicated, but in which what changes above all is the dominant characteristic, or more exactly, the system of correlation between juridico-legal mechanisms, disciplinary mechanisms, and mechanisms of security. In other words, there is a history of the actual techniques themselves. [Foucault 2007:22] 
From the sociological viewpoint, it is worth looking into the social distribution of the techniques of power. Obviously, not all situations in modern society can be controlled by means of the techniques of "governing through freedom," such as, for example, mentoring or coaching. We are familiar with situations that are controlled by the penal code and we also are aware of the strict surveillance of conduct in public places. Another question arises (relevant not only from the sociological, but also political point of view) concerning the distribution of power within a given framework of a social structure. Not all participants of social life can or wish to be included in the techniques of "governing through freedom." In other words, not everyone is able to or willing to become "entrepreneurs of themselves" (Foucault 2008:226). This does not only mean free-market entrepreneurship in the strictly economic sense of the word, but a more broadly understood entrepreneurship, initiative, flexibility, and responsibility in the area of managing one's own professional career, in the field of civic activities, in areas of our private life, personal relationships, or caring for one's physical condition.

When analyzing power relationships in contemporary society, one needs to avoid any mental shortcuts or sociological hypostases such as "risk society," "knowledge-based society," or "postmodernity." Instead, it is worth looking into "the emergence of new control strategies and the reconfiguration of old ones," with the former connected to social inclusion and the latter to exclusion (Rose 2004:240). Institutional and media promotion of new techniques (techniques of "governing through freedom") is not suitable for everyone, and it may even contribute to deepening the already existing social discrepancies. As Rose notices (2004:259), it appears as though outside the communities of inclusion exists an array of micro-sectors, micro-cultures of non-citizens, failed citizens, anti-citizens, consisting of those who are unable or unwilling to enterprise their lives or manage their own risk, being incapable of exercising responsible self-government, attached either to no moral community or to a community of anti-morality.

In the summary to the lecture of April $5^{\text {th }}, 1978$, Foucault states that a new type of knowledge has emerged from the new and liberal art of governing that was introduced in Western Europe at the end of the $18^{\text {th }}$ century. It both claims to have the status of a science and, additionally, is considered to be "indispensable for good government." What is an important feature of this knowledge, however, is the fact that "this is not a knowledge of government itself, its knowledge, so to speak, is knowledge internal to government." In other words, this type of knowledge does not concern the "art of government" itself, but is, "as it were, tête-à-tête with the art of government." On the one hand, this knowledge may be practiced as a science, that is, as a scientific theory, based on cognitive motivation, separate from practical applications as part of the art of governing. Nevertheless, it does appear that even in such a situation "government cannot do without the consequences, the results, of this science" (Foucault 2007:449-450). Foucault draws attention to economics as a field of science that is of crucial importance in the era of governmentality, particularly in the series of lectures entitled Birth of Biopolitics (2008). Obviously, economics is such a science that may be practiced for cognitive purposes, however, it is also science that is strongly connected with the modern art of governing, enabling better responses to the demands for the credible diagnosis of socio-economic threats; offering recommendations concern- 
ing the directions which would ensure the safety of the population-including helping plan and introduce appropriate economic policies.

It is worth considering the ways in which, 40 years after the quoted lecture, this, as Foucault (2007:450) says, "rather peculiar relationship between knowledge and power, of government and science" manifests itself. Certainly, it still concerns the political economy, as well as other branches of economic sciences. However, it also seems to have moved into other fields of scientific research, taking on various formulae of social relations. On the basis of the concept of governmentality, at least four directions and methods of manifesting relationships between the art of governing and knowledge can be distinguished.

A. What is highlighted in the field of governmentality studies is the conviction of the "economization of the social" (e.g., Bröckling, Krasmann, and Lemke 2000). According to this view, variety in social life falls prey to uniformity dictated by the economics of productivity and the assessment of measurable benefits, while, at the same time, espousing the slogans of autonomy and the sense of agency of the individual (see, e.g., Miller and Rose 2008).

An important premise of the "economization of the social" is the blurring of the lines between the area of work and that of leisure time activities (Lemke 1997:255-256). On the one hand, the aim of leisure time is no longer solely relaxation and rest, but more and more often the acquisition of communicative and interactive skills (e.g., learning a foreign language or team-working skills), as well as mental skills (e.g., flexibility in reacting to new situations or resilience in stressful ones) that are needed at work. On the other hand, the "personal" aspect is intro- duced into the area of work (for example, through introducing flexitime, establishing small groups of employees, or increasing the pressure to be innovative, creative, and on developing personal communication skills or mental resilience among employees). This trend has led to employee efficiency being increasingly assessed by evaluating them as people and whether they use their leisure time as an opportunity to increase their human capital.

Another aspect of the "economization of the social" is the process of the marketization of areas that were once treated as fields of independent symbolic activity. The mechanisms of promotion and marketing have not only entered the world of art with a vengeance but has also led to academic science being increasingly required to increase its output, efficiency, and practical application. Both a piece of art and scientific work are being subjected to criteria that are, supposedly, objective because of being quantitative. The value of a piece of art is measured by its price and popularity, whereas the value of scientific work is evaluated based on the extent of a researcher's participation in large research projects and the citation rates of their publications. In both areas, management regulations are introduced that are similar to those that are applied in the economic field, and, in the place of genuine artistic or scientific invention, so-called creativity which relies on social opportunism and the willingness to follow the neoliberal rules of the game is rewarded.

B. Also, the thesis of Nikolas Rose (e.g., 1996) should be noted, according to which, roughly since the middle of the $20^{\text {th }}$ century, the advancing processes of therapeutization and psychologization of social life have been taking place in Western civilizations, particularly through the growing importance of "psy" sciences (psychology, social psychology, psychother- 
apy) which offer their expertise on psychic phenomena. In my opinion, however, psychological sciences play neither a key role in organizing social life nor in organizing public discourses. Instead, they fulfill an indispensable service or "tool" function in economic sciences (e.g., in the form of business psychology, which studies, for example, the optimal ways of motivating employees), political sciences (e.g., in the form of political psychology, which studies, for example, political attitudes and the preferences of the potential electorate), and the science of education (where the issue of psychology is obvious). Psychotherapy has a particular status that of the institutionalized and scientifically legitimate practice that serves to reduce any mental discomfort of individuals and, through this, lessen the obstacles that impede the safe functioning of the population.

C. It is also worth noting both the scientific current of critical reflection and studies within social pedagogy that points to the "educationalization" process (e.g., Simons and Masschelein 2008) inspired by the concept of governmentality. It appears that due to the concept of educationalization, the issues analyzed as economization and psychologization receive a particularly accurate reformulation and significant complement.

Educationalization means transferring images and pedagogical categories into spheres of life that are basically unrelated to educational activities, such as economy, politics, civic society, culture, or private life. In this way, issues that were part of non-pedagogical areas of social life undergo a process of reformulation and become pedagogical issues (see: Höhne 2003; Czyżewski 2013a).

This particularly concerns the neoliberal educationalization that distances itself from formalized and insti- tutionalized patterns of school education based on an asymmetric teacher-student relation and fosters active learning supported by advisors, coaches, and mentors that remain in seemingly dialogue and symmetric relations with their clients (e.g., Masschelein et al. 2006). Moreover, neoliberal pedagogization (initially, a subversive, fringe alternative) has emerged from the polemic dispute with institutional pedagogy. With time, its keywords and ideas have become the new dominant discourse, the evidence of which is widespread recognition that it evokes and any lack of serious attempts to discredit it. In this way, the powerful influence of pedagogy and its cognitive and practical perspective on contemporary methods of implementing and sustaining power relationships is clear.

D. Perhaps this fusion of economics and pedagogy will one day become a scientific discipline, despite being a vision that is rather unrealistic nowadays. Before this topic is put to bed, however, it is time to look into our own backyard and question the place of sociology in the relationship between the modern art of governing and science. One may wonder why this is not such a frequently discussed issue among sociologists themselves. Especially that contemporary sociology seems to be playing the "tête-à-tête with the art of government" mentioned by Foucault particularly eagerly, and is far from being cognitively innocent. Instead of the previous unity or mixture between power and knowledge (or science and the art of governing) the separation and also mutual dependency of both areas comes in. If (and this is a fact) the sociological analyses of "social capital," "innovation," "agency," or "trust" are devoid of self-critical reflection-with the entanglement of these analyses in the symbolic service of neoliberal capitalism-then it is impossible to resist the thesis regarding the cognitive and political opportunism of the vast majority of contemporary sociology. 


\section{Governmentality and Contemporary Sociology}

The problematic relationship between governmentality and sociology deserves a closer inspection. Firstly, it concerns the process of the selective mainstreaming of the internal criticism of sociology. In the 1960s and 70s, a wave of criticism of the main streams of sociological theory and the standard methods of social research at that time swept through firstly American and then European sociology. In fact, it was not so much a criticism of sociology itself as it was a self-criticism by sociologists themselves. The authors of these accusations and concerns (e.g., Harold Garfinkel, Aaron Cicourel, Erving Goffman, Herbert Blumer, Anselm Strauss, Alvin Gouldner, and Pierre Bourdieu, as well as their followers) questioned those areas of sociology that formerly had been commonly thought of as its paramount accomplishments, though each from a different angle and frequently indirectly. It is worth adding, however, that these authors were more engrossed in formulating new and alternative directions of sociological inquiries, the productivity of which was only possible thanks to the fact that by not agreeing with the dominant approaches to practicing sociology, new alternative ways were, thus, elaborated.

Since then much has changed in sociology. A number of new ideas (which were previously treated distrustfully or even ironically) have made their way into the main streams of sociology. These include something as obvious today as the role of patterns of interpretation in shaping social reality or the presence of the new methods of qualitative research that many research projects are equipped with nowadays. Nevertheless, the far-reaching acceptance of these ideas came at great cost, that is, the neutralization of the critical, sometimes even subversive, potential that lies within them. Moreover, contemporary social sciences (as well as humanities) tend to be absorbed in the compulsive production of texts and research reports and in the promotion of more and more new "turns" (e.g., the cultural turn, visual turn, performative turn, etc.) rather than in genuine intellectual ferment and invigorating contestation. Innovation has been reduced to fit in with the requirements of marketing and the promotion of one's own publications, as well as the, supposedly, original orientations and approaches that are presented there.

The above-mentioned wave of criticism was both diverse and partly also conflicted. One of the commentators (Zaner 1973), while making a necessary simplification of the big picture, emphasized two currents; referring to them as radical (phenomenological) and political criticism. The former focuses on the rules of interpretation and the structures of experience based on the phenomenological inspiration that is rooted in Kant's concept of the conditions of possibility and defining the frames of specific acts of experience. Different branches of interpretive sociology such as ethnomethodology, phenomenological sociology, or, to some extent, symbolic interactionism may serve as examples. Political criticism refers to Marxism and neo-Marxism, by Antonio Gramsci in particular, and draws attention to the inevitable ideological bias of social sciences, as well as to the need for the political engagement of sociology. Alvin Gouldner was a famous advocate of that perspective in the 1970s. Both types of criticism competed with each other for the title of true criticism, acknowledging the adverse solution as a seeming one. I recall the conflict at that time and, in my opinion, nowadays, we are in need of a criticism that would combine the interpretive and political aspects while at the same time proposing a new viewpoint based on a thorough redefini- 
tion of the "interpretive" (which is associated with knowledge) and the "political" (which is associated with power). It is my presumption that the concept of governmentality may offer such a holistically critical approach.

Besides, the perspective of governmentality and, more broadly, using Foucault's basic categories, makes it possible to look at the process of the selective mainstreaming and domestication of interpretive sociology within contemporary sociology with hindsight. Hence, it may be said that in their simplest social context, interpretive notions (such as the ethnomethodological concept of reflexivity, the phenomenological concept of reciprocity of perspectives, and the social construction of reality, or symbolic-interactionist concepts of self, symbolic interaction, and negotiated order) expressed resistance towards the mechanisms of sovereign and disciplinary power. Moreover, interpretive perspectives in sociology show that social order is always constructed gradually-in and through situated interpretive processeseven when one may have the impression that human actions are subject to structural determination that are external to them. In this way, interpretive sociology brought with itself the ideological message that every social order, even the most oppressive one, may be questioned from within. However, when interpretive notions were transferred to the sociological mainstream, they became part of the discourse on governing through freedom, which is a "soft" and indirect type of power relation, although it is equally as invasive as that of sovereign or disciplinary. It can thus be stated that in recent decades the social function of notions and ideas rooted in interpretive sociology has changed quite imperceptibly. ${ }^{1}$

${ }^{1}$ The category "change of function" was introduced by Karl Mannheim (1952:188-189). For more comments on the change of function of interpretive perspective see: Czyżewski 2013b.
A similar process took place in management science. In the 1960s and 70s, critical theory expressed its disagreement with the bureaucratic, anonymous, and schematic style of management in the area of business and advocated an increase in the area of employees' autonomy, as well as allowing them flexibility when realizing their tasks. As proven by Luc Boltanski and Ève Chiapello (2005), in the 1990s, management science adopted these ideas and reformulated them as the golden rules of "the new spirit of capitalism," fostering employees' innovation within flexible teams and projects. In a true Foucauldian manner, it should be added that "the new spirit of capitalism" can be considered a variety of governmentality which, in turn, (as every formula of power) maps out the spheres of exclusion. In this case, exclusion may pertain to those individuals who are unable to, or will not, fulfill the requirements of so-called creativity, empowerment, and self-responsibility.

Secondly, the selective mainstreaming of interpretive sociology is accompanied by the incredible and-for many reasons-a troublesome career of the term "agency" as part of the theoretical language of contemporary sociology. The term and the idea of "agency" became fashionable in sociological discourse in the 1980s together with the proliferation of the "agency-structure" theorem proposed by Anthony Giddens (1984), which was originally intended to bridge the gap between "subjectivist" (too strongly "agency"-oriented) and "objectivist" (too strongly "structure"-oriented) sociological orientations. It might be arguably demonstrated that the "agency-structure" theorem was based on a substantial misinterpretation of both parts of the formula.

More specifically: the idea of the agency was certainly a salient feature of symbolic interactionism, espe- 
cially in Herbert Blumer's version of this perspective. Giddens' phrase "subjectivist" in the case of symbolic interactionism is not a mistake. Whereas the situation is different with ethnomethodology, which was labeled by Giddens (in this case erroneously) as a supposedly "subjectivist" approach, despite having clearly distanced itself from the notion of agency by offering a novel approach to the self-organizational character of communication. Similar distortions were associated with Giddens in reference to approaches which he called "objectivist." Certainly, it is easy to find examples of the objectivist perspective on social structures, but the key variety of sociological structuralism, namely, the structural functionalism of Talcott Parsons, was intended to distance itself from sociological "objectivism" by offering a generalized approach to the analytically abstracted dimensions of social life. In other words, it may be asserted that the insights of some of the innovative sociological approaches have been significantly distorted while attempting to domesticate them within (and adjusting them to) the sociological mainstream.

It is not only worth considering whether the notion of agency or the "agency-structure" dilemma may be an intellectual fallacy. It may well be that the social and political costs of this fallacy also need to be addressed, especially as "agency" language proves to quite neatly fit into neoliberal discourse promoting "empowerment," "flexibility," "creativity," "participation," and, last but not least, "agency." Instead of offering new conceptual and methodological tools for the study of "agency," as present in neoliberal forms of economic and social life, both sociological theorizing and research focused on "agency" have instead become a part of the problem which needs to be analyzed.

Widely and uncritically used words are a sign of linguistic habit. And a linguistic habit that is present in many statements, particularly influential ones, indicates patterns of discourse. As pointed out by many authors, the alleged obviousness of discourse is usually a display of its cultural dominance. It is, therefore, important to ask questions that go "against the current" of fixed habits of communication. Since the discourse of "agency" has been given the status of obviousness in contemporary sociology, this fact should lead to a skeptical reflection of the fusion of the cognitive, social, and political costs of "agency fallacy."

The concept of "agency" (individual or collective) as one of the salient characteristics of contemporary sociological theorizing is, to some extent, a rather troublesome result of a half-way attempt at the fluidification and de-essentialization of the social-scientific picture of contemporary social reality. A possible way out of the intellectual and political predicament caused by the "agency fallacy" may be found in Foucault's concept of "subjectification," which plays a central role in the entire oeuvre of Foucault. It is also crucial from the point of view of the present argument, as it makes it possible to overcome the classical sociological "actor vs. situation" frame of reference.

"Subjectification" (quite an unusual word) is the English translation of the French term "assujettissement," the literal meaning of which is "subjection" or "subjugation." A literal translation of the Foucauldian "assujettissement" as "subjection" can be found, although it is not an ideal solution. In Foucault's case, it is more important that the notion of "assujettissemant" contains the word "sujet" ("subject"). Hence, the somewhat awkward neologism "subjectification." In Foucault's own formulation it is exactly this notion that concerns the main focus of his research interests, that is, to "a history of the dif- 
ferent modes by which, in our culture, human beings have been made subjects" (Foucault 1982:208). In the formulation of Nikolas Rose (2004:58), the main research question is as follows: "What kinds of human beings have we come to take ourselves to be?" Foucault was primarily concerned with the history of different varieties of "subjectification," and it was from this perspective that he looked at the issue of power. In other words, he argued that the ubiquitous processes of "subjectification" always take place within the relations of power. Just as social forms of power change historically, so do the socially-shaped variations of subjectivity.

Combining all the elements of the arguments above, it may be concluded that governmentality, the leading theme of Foucault's lectures in 1978-1979 (Foucault 2007 and 2008), and of governmentality studies is-paradoxically-nothing but a complex method of indirectly governing a population by equipping individuals and groups with a sense of agency. If we understand governmentality as a formula for indirectly governing the population by means of the self-government of workers and citizens, then the following conclusion appears inevitable: The contemporary idea of "agency" is an "idol" in its classical Francis Bacon's sense: a well-established but mistaken illusion. However "agency" is both something else and something more. The idea of "agency" is not only, and not really, an ideology supporting new varieties of economic activities, new developments in management, and-last but not least-new trends in popular culture. In the Foucauldian frame of reference, "agency" is primarily a social "apparatus" of power (in the terminology of Foucault a "dispositif" of power)-that is, a complex set or ensemble made up of discursive elements (such as diverse texts, including sociological formulations), as well as non-discursive ones (such as models of social organizations and institutions, etc.), which together make up a mechanism of social constitution and application of power relations (cf. Foucault 1980a).

The third aspect of the problematic role of sociology in relation to the contemporary "art of government" is the marginalization of the issue of power, which is accompanied by the misleading interpretation of the changes which Foucault supposedly introduced into his concept of power relations in the late 1970s. In the reception of Foucault's oeuvre a twopart scheme of interpretation was perpetuated. In the early and middle period of his career, Foucault was to reject the idea of the autonomy of the subject altogether and treat subjectivity solely as a product of power relations. The concept of disciplinary power and its correlation in the form of a docile subject were supposed to have been the final word on this viewpoint. In the late 1970s, the so-called "late" Foucault was to step away from the previously predicated vision and open up more and more to the issue of freedom and agency. What is more, it is sometimes conjectured that the "late" Foucault, just like the prodigal son, came to terms with liberal thought. In his new approach, the areas of the self-realization of a subject were not supposed to be unlimited or easily accessed, however, the subject could and should find and cherish them. This pattern of interpretation appears in many books on contemporary sociological theories and in numerous other publications.

The readiness with which this pattern is accepted may raise concerns, particularly when it is compared with a thorough reading of Foucault's texts and lectures. It does appear that basic elements of this pattern have their roots in interpretative simplifications and mistakes. For instance, a more indepth reading of Discipline and Punish (Foucault's best-known book, which is the crowning achieve- 
ment of the "middle" phase of his activity), does not confirm what many commentators imagine about the totalizing character of disciplinary power. Since such an idea is mistakenly attributed to the "early" and "middle" Foucault, then perhaps Foucault's actual "late" shift of interest towards ethical issues may also be mistakenly interpreted as walking away from this totalizing vision after becoming convinced of its limited, and therefore less oppressive, influence. In actual fact, by analyzing the whole of Foucault's work, we are justified in accepting the opposite thesis, developed, for example, by Jeffrey Nealon (2008). According to this thesis, not only do the texts, lectures, interviews, and other statements from subsequent periods of Foucault's career not fit in with the already mentioned fundamental re-evaluation of the concept of power or with the development of Foucault's perspective, but they also serve as evidence of the immutability of its main assumptions. Moreover, they also justify the supposition that a, paradoxical, process of intensification of power relations has been taking place throughout the course of history, during which power has become less visible, but by no means less invasive. The advancing intensification of power means its "abstraction, lightening, extension, mobility, and increased efficiency" (Nealon 2008:32).

It seems that the concept of governmentality outlined above is well-suited to the thesis of the historical process of softening and intensification of the techniques of power. Together with the ever-broader introduction of "governing through freedom," the motivation of individuals to social conformism also changes. The motif of fear of punishment created through sovereign power and the pursuit of self-discipline through discipline power is accompanied by the illusionary sense of agency, self-realization, and subjective autonomy.
A two-part interpretation is still commonly treated as plausible. An effective obstacle to questioning it are the hackneyed patterns of common sense and sociological reasoning. Commonsensical beliefs and sociological theorizing (including the so-called critical theory which, in that matter, has lost its critical edge) share a predominant presumption that a fundamental contrast exists between power, oppression, and subjection on the one hand, and agency, emancipation, and autonomy on the other. A similar contrast is noticeable in the opposition of "agency" and "structure" in Giddens's "agency-structure" dilemma. Critical theory and its numerous offshoots postulate the emancipation of agency from the pressure of various restrictions. Giddens suggested overcoming the agency-structure dilemma by using a theoretical "third way" in the form of structuration theory (Giddens 1984) and the concept developed later, namely, "late modernity," based, inter alia, on the idea of individual and collective identity projects (Giddens 1991).

Each of these solutions has become (in one way or another) a variant of the contrast between agency and power, or agency and structure. This could not be more wrong, agree Rose and Foucault. To quote from Nikolas Rose again (2004:54-55):

all the essential, natural and defining conditions that tend to be ascribed to the human world-modern forms of subjectivity, contemporary conceptions of agency and will, the present-day ethics of freedom itself-are not antithetical to power and technique, but actually the resultants of specific configurations of power, certain technological inventions, certain more or less rationalized techniques of relating to ourselves. One cannot counterpose subjectivity to power, because subjectification occurs in the element of power; one cannot counterpose freedom to tech- 
nology, because what we have come to understand as our freedom is the mobile outcome of a multitude of human technologies.

Perhaps surprisingly, certain journalists seem to have a greater understanding of this question than the majority of sociologists, psychologists, and pedagogues. A short and controversial text written by Martin Lukacs (2017) is a fitting example of that. Lukacs points to the deeper meaning of fostering ecological awareness; understood as the moral obligation of individuals to undertake various initiatives in the area of "greening" one's personal life. The nobly motivated efforts of an individual have little value when contrasted with the effects of those branches of the economy that systematically and on a giant scale contribute to climate change. Placing the responsibility for climate change on individuals fits in perfectly with the individualistic social philosophy of neo-liberalism. One would wish to add that (after Foucault): ecological awareness examined not from the perspective of even the noblest motivation of individuals, but from the perspective of its social function turns out to be (paradoxically and contrary to the intentions) yet another $\operatorname{cog}$ in the smoothly working mechanism of governmentality. The sense of emancipation and initiative (e.g., as a result of introducing changes in lifestyle that were the consequence of one's own decisions concerning diet or transport choice) is not contrary to power relations but its necessary component.

Despite this, contemporary sociology insists (to a great extent and independently of sometimes deep theoretical and methodological differences) on the traditional conviction that the basic frame of reference of social sciences should be contrasting the individual and society; independent of social pressures and our succumbing to them; freedom and oppression; or subjectivity and power. The consequence of insisting on such a position is the unconditional glorification of such values like empowerment, resilience, agency, autonomy, and participation. Ipso facto, the extensive field of neoliberal techniques of power based precisely on these values is treated with admirable naivety as a result of the liberation from power relations. And as the share of "governing through freedom" in the total repertoire of contemporary techniques of power increases, the ability of sociology to trace power relations in social life then decreases to the same degree-even, or perhaps especially, with reference to the situations seen by the majority of society or the actors themselves as that of free, autonomous activity. By marginalizing the role of power in contemporary society, sociology loses its critical overview of reality. Instead, it adopts and develops the language used in reform-oriented movements in politics, economy, technology, management, mass media, and popular culture. In this way, sociology becomes part of the problem it should be analyzing. Therefore, the question arises of whether it is not true that sociology should become a subject of any critical overview in discourse and dispositive analysis, standing on par with other areas of social reality (cf. Czyżewski 2019).

\section{The Question of Truth: Foucault's Perspective and Transformations of Contemporary Culture}

The lectures on governmentality from the years 1977/78 and 1978/79 (Foucault 2007 and 2008) referred greatly to modern times, partly to the latest events (since they were about the period post World War II in Germany and the United States). As I have pointed out previously, the conceptual categories suggested during these lectures were useful in nu- 
merous analyses of social reality at the turn of the $21^{\text {st }}$ century, evidence of which can be found within governmentality studies. The course of 1979/80 (Foucault 2014), on the other hand, brought about such an important displacement of the center of gravity that it must have been a surprise for the audience gathered at the Collège de France. As if the fact that the subsequent series of lectures (including those from 1980/81, 1981/82, 1982/83, and the final one from 1983/84; see: Foucault 2017; 2005; 2010; 2011) concerned mainly ethical and subjectivity issues (totally excluding the socio-economic issues) was not enough, this topic displacement was accompanied by a sea of change in its historical context. Beginning with the course in 1979/80 (On the Government of the Living [Foucault 2014]), the topic of the lectures was restricted entirely to the culture of late antiquity and any possible references to contemporary times were left to the recipients' interpretation.

An attempt at explaining these re-evaluations was offered in two lectures given in Dartmouth in November 1980-that is, after the course in 1979/80, but still before the course in 1980/81 (Foucault 1993). Foucault admitted there that, with time, he had become increasingly aware of the fact that as well as "techniques of domination of individuals over one another" the "techniques of the self" ought to be included, that is, the techniques of the individual's effect on themselves. It is worth emphasizing again that, in this context, Foucault does not mean the subject's activities being free from any social influences, but rather how an individual's effect on themselves is included in the mechanisms of social control and coercion. Thus, it is still about "government," which Foucault now describes as "the contact point, where the way individuals are driven by others is tied to the way they conduct themselves" (Foucault 1993:203).
Along with this shift towards the "techniques of the self" in Foucault's late lectures, changes appeared in the analytical instrumentarium concerning knowledge. The notion of power/knowledge which was, thus far, the key one, disappears, ${ }^{2}$ and in its place, a new approach to the topic of truth arises. The topic of the truth, or rather the social construction of what is regarded as the truth, had occupied Foucault since the beginning of his scientific activity. However, until the turn of the 70s and 80s, the truth had been expressed to its fullest in the phrase "regime of truth." And it was through this phrase, in an interview in 1976, that Foucault showed that (contrary to popular belief) truth was not a result of being freed from power relations, but-on the contrary-it was the result of power relations in a given society. In other words, "truth" is not the truth of reality but "is to be understood as a system of ordered procedures for the production, regulation, distribution, circulation, and functioning of statements" (Foucault 1980b:133). Therefore, "truth" is indeed the "regime of truth." Importantly for the disquisition presented herein, Foucault (1977:13) invariably claimed that "each society has its regime of truth, its 'general politics' of truth."

As part of his lectures in 1979/80 (Foucault 2014), the subject of analysis was the key practices of early Christianity: acts of belief and acts of confession, understood as acts of a subject within the oppressive regime of truth. It could be said that here Foucault brings about an extreme radicalization of the earlier phrase, "regime of truth." Later on, in his lecture courses in 1980-1984, the subject's "own" truth

\footnotetext{
${ }^{2}$ Strictly speaking, in the first lecture of the series entitled "The Government of the Living," Foucault eschews using the notion of knowledge/power and names it "the now worn and hackneyed theme" (Foucault 2014:11). As Michel Sennelart explains, the term coined by Foucault that is still used today, that is, power/knowledge, was used by Foucault from 1972 until the mid-1970s. Then it began to be replaced by knowledge/power (Sennelart 2014:338-339 and 352).
} 
becomes the topic of analysis, though from the perspective of late antiquity, particularly through stoic thought, along with the ancient idea of truth-telling ("parrhesia"). Truth acts may, then-to a lesser or greater extent-be the results of "techniques of domination" or "techniques of the self." Yet, regardless of the fact that "truth" is more the result of techniques of dominance or techniques of the self, it is not about the relationship of an utterance or a text to reality, but about how, in acts of truth, our relationship to ourselves is expressed.

Foucault's late reflection on acts of truth attracts criticism from at least two perspectives. Firstly, by concentrating on acts of truth, it may lead to marginalizing the question concerning whether a statement is true (in line with reality) or not. Certainly, this happens to acts of belief and acts of confession. The situation is more complex when it concerns being truthful, however, since the main feature of such statements is, according to Foucault, not limited to the courageous preaching of uncomfortable views, even if it means exposing oneself to serious inconvenience or danger. Being truthful assumes an accurate understanding of reality. However, the dominating feature of parrhesia is remaining true to oneself against all the odds. It is worth stressing that (contrary to Foucault and his successors) a value dismissed much too often is the plain truth as a statement in line with reality. Bernard Williams quite rightly points to the significant role of communicating these "plain truths"-little truths about common, everyday matters and situations. However, he notes that scientific work should not be limited to formulating plain truths because its mission also concerns elaborating broader interpretations that were susceptible to being called into question (Williams 2002:1-19). Following in the footsteps of Bernard Williams, Tony Judt reveals the tension between truthfulness, that is, respecting "smaller truths" concerning facts and following the requirements of "higher truths," for example, loyalty towards a suitably understood raison d'être (Judt and Snyder 2012:287 and 309-310). The immense social need for an interpretation of the current or historical political processes concerns not only scientists, but also intellectuals and the symbolic elites in general (e.g., journalists, politicians, and the clergy). What seems particularly dangerous in this respect is the bending or even warping of facts in the name of proclaimed ideas and outlooks.

Secondly, the appeal to respect plain truths and cherish the two virtues of truth, "Sincerity" and "Accuracy" (Williams 2002:84-148), has become of particular importance in today's culture, where manipulation, bare-faced lies, and indifference towards the truth of a statement is commonplace. However, the normative validity of the postulate does not prejudge its implementation. In fact, the more rarely the postulate of telling the truth is implemented, the more important (or normatively more legitimate, so to speak) it seems. Hence, if aiming at being truthful is not an axial feature of contemporary culture, then the notion of telling the truth may be only partially useful when analyzing reality. Reconstruction of the patterns in the attitude to the truth that dominates in contemporary culture requires different approaches.

Two ideas provide inspiration here, the first of which has long been unappreciated. The humble essay On Bullshit by Harry Frankfurt only became well-known in the $21^{\text {st }}$ century, despite being published in 1986 (Frankfurt 2005), as this is when cultural reality caught up with the diagnosis suggested by Frankfurt. Interestingly, it was a philosopher, not a sociologist who offered such a great dose of sociological imagination. Frankfurt makes a distinction 
between a liar and a bullshitter, explaining that they both deceive us, but in two different ways. A liar hides the fact that he is lying, that he consciously and deliberately does not tell the truth, whereas a bullshitter hides the fact that "the truth-values of his statements are of no central interest to him; what we are not to understand is that his intention is neither to report the truth nor to conceal it" (Frankfurt 2005:55). For a liar, therefore, truth is-paradoxically-still an important point of reference because a liar wants to secretly deny it and, in this way, mislead us, while the truth is irrelevant for a bullshitter. Although it may happen that a bullshitter is telling the truth, it does not matter to them whether they are lying or not. Although Frankfurt noticed the rise of the phenomenon of bullshitting as early as the 1980s nowadays we may talk about its real invasion. Today, we are all aware that the omnipresence of bullshitting in contemporary culture is supported by, for instance, technological and business mechanisms of media communication-the Internet in particular.

The other idea is more commonly known. Between 2016-2017, in the context of such media events as Donald Trump's tweets or the arguments disseminated by the supporters of Brexit, the notion of "post-truth" went viral. Oxford Dictionaries defines "post-truth" as "an adjective relating to circumstances in which objective facts are less influential in shaping public opinion than appeals to emotion and personal belief" and declared the term Oxford Dictionaries' international word of the year 2016. ${ }^{3}$ The rise of the phrase "post-truth" (or "posttruth") happened overnight, it appeared and expanded at an incredible pace, only to virtually disappear from

\footnotetext{
${ }^{3}$ See: https://en.oxforddictionaries.com > word-of-the-year-2016 [Retrieved October 16, 2016].
}

public space. The speed at which the once fashionable term "post-truth" (and its equivalents in many languages worldwide) vanished, was not unrelated to its previous inflated use that frequently, quite wrongly, identified post-truth with a lie, a con, or preaching an untruth. Additionally, the phrase "post-truth" was used as an invective in political clashes. Consequently, the notion "post-truth" was discredited, considered as a phrase no longer useful to describe the all too well-known phenomena.

It is worth stressing the difference between what, on the one hand, is associated with the phrase "post-truth," that is, the inflationary and indiscriminating journalistic use of this notion and, on the other hand, the distinct meaning of the phrase "post-truth" and the attempts to apply it when analyzing the transformations in contemporary culture. There have also been numerous academic attempts to apply "post-truth," of which even a brief overview would stretch beyond the limitations of this text. Jason Harsin (2015), a media expert, put forward an especially interesting suggestion of an analytical approach to the phenomenon of "posttruth" when pointing to the key role of the attention economy in contemporary culture. ${ }^{4}$ Together with the development of digital communication technologies, the dissemination of their passive and active access, as well as the saturation of public space with huge amounts of information, the issues of the authenticity of this information and the truthfulness of the sender have become less relevant. The criterion of the relevance of information is based only on whether or not it draws attention to itself and holds this attention-if only for a short while. As Harsin notices, we are faced with regimes of truth, that is, the social mechanisms of establishing what should

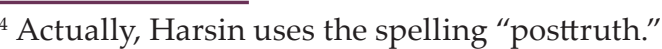


be seen as truth, giving way to post-truth regimes, that is, the social mechanisms of attention management. According to Frankfurt's anticipating intuition, patterns of communication are developing on a massive scale right before our eyes. And within those patterns, it is irrelevant whether a piece of information is true or not. What is important in the process of communication, however, is the element encapsulated in the above-quoted definition from Oxford Dictionaries, namely, "appeals to emotion and personal belief." One should not, however, be deluded: although many users of digital communication suggest or even try to assure us that they are telling the truth, it is not usually about truth or truthfulness. The regimes of truth have lost their function of a general criterion of the validity of information, and instead gain the status of solutions appropriate for specific cultural niches, such as scientific or court proceedings, or religious life. These niches remained relatively isolated islands in the sea regulated by the principle of post-truth.

\section{Towards a Genealogy of the "Post-Truth" Society}

There is no end to our inquiries: our end is in the next world. When the mind is sated, it is either a sign of diminished faculties or weariness. No powerful mind stops within itself: it is always stretching itself and expanding its capacities. It makes sorties which go beyond what it can achieve: it is only half-alive if it is not advancing, pressing forward, getting driven into a corner and coming to blows; its inquiries are shapeless and without limits; its nourishment consists in amazement, the hunt and uncertainty. [Montaigne 1993:1211]

These words, written in the $16^{\text {th }}$ century, accurately present the passionate pursuit of truth that was so characteristic of the whole period of modernity. Re- called today, these words allow us to realize that the pursuit of truth is not a dominant feature of contemporary culture, even if we assume that the pursuit of truth does not mean establishing the facts, but what should be established as truth. It is thus because contemporary culture has become indifferent to the issue of the truthfulness or falsity of statements concerning reality. It has been a long-term process which has gone through several stages: from the recognition that knowledge, inevitably, has a perspective character, through locating these sources of perspectivity of knowledge in the sphere of group interests or individual psychological mechanisms, abandoning truth for the principle of honesty, and finally, to the invasion of post-truth and bullshitting.

Frankfurt (2005:33) recognizes the "lack of connection to a concern with truth" as the essence of bullshit. This "indifference to how things really are" (Frankfurt 2005:34) is also an important feature of post-truth. One may seek the answer to the question of which factors may favor the dynamic expansion of such a tendency in many ways, three of which seem most significant.

Firstly, technological and organizational transitions in the field of mass media have led to a proliferation in the number of dispersed and unrelated messages which are offered to the recipients in the public space. They also favor "prosumption" (which means that more and more ordinary citizens are becoming not only consumers, but also producers of messages). Thus, the inclination of ordinary citizens to make their voices heard on matters they know nothing about is enhanced. What matters is one of the two virtues of truth indicated by Williams (2002): "Sincerity." Following the other one, "Accuracy," is not required. Frankfurt also talks about two ideals that refer to the truth, however, in his case, along 
with "sincerity" comes "correctness" (in his essay, the term is related to the notion of "Accuracy"). His judgment of relations of the two ideas brings the matter to a head. In his view, "a retreat from the discipline required by dedication to the ideal of correctness to a quite different sort of discipline, which is imposed by pursuit of an alternative ideal of sincerity" is taking place. In these circumstances, as Frankfurt ironizes, "sincerity itself is a bullshit" (Frankfurt 2005:65 and 67). However, to put it more precisely, bullshit (or post-truth), that is, talking without concern for the truth, should be distinguished from telling one's own truth (i.e., favoring sincerity without being concerned about accuracy or correctness). To recapitulate, one may point out at least three kinds of failure to meet the rigors of the pursuit of truth: bullshit (or post-truth), telling one's own truth, and simple lying. The rise of all these three phenomena seems to be facilitated by the recent developments in mass communication, especially by the digitalization of public space.

Secondly, one may take a step further and assume that transitions in the field of media, and-more broadly-culture as a whole, do not take place in a vacuum, but are related to changes in social organization, in the field of power relations in particular. Harsin (2015), whom I mentioned earlier, talks about regimes of post-truth. An important supplement to Harsin's reasoning is the concept of another philosopher, Bernard Stiegler (e.g., 2010). In his polemic with Foucault, Stiegler argues that we are presently dealing not so much with biopower, but with psychopower. Psychopower has become the main function of biopower and it is based on the implicit and anonymous managing of our dispersed attention, which-as a consequence-leads to the destruction of attention, that is, stupidity, manifesting itself in the inability to connect information and, as a result, to irresponsibility and incivility. It is worth noting that both regimes of post-truth and psychopower provide individuals with the illusionary feeling of the agency while in fact indirectly guiding their conduct-thus both regimes of truth and psychopower may be thought of as mutually affined manifestations of governmentality.

Finally, it is important to consider the relationships between the abatement of regimes of truth combined with the formation of regimes of post-truth and transformations in various spheres of symbolic culture. As is already well-known, not only is the cultural sphere witnessing the contestation of the traditional, hierarchical division into "high" and "low" culture, but also the impugnment of the terms used to describe this division. Assessment of the artistic message nowadays relies on the freely expressed, subjective feelings of laypeople. These opinions are deemed equipollent to the professional, formal criteria which were previously considered sacrosanct. The opinions of individual recipients are tallied up, and the most popular choice becomes the objectivized criterion for the evaluation of the artistic message. This measure is not permanent and undergoes fluctuations in line with changes in the audiences' preferences. Among the plethora of information available in the media, the audience may also find data on the growth or decrease in the number of the so-called "likes." 5 Substantial parts of Western civilization are undergoing significant transformations in the realm of religiousness. A clearly noticeable crisis is being reported among Christian denominations, especially Catholicism. Paul Veyne (2010) persuasively shows that it was such features as its holistic, pervasive worldview, access to a universal community,

\footnotetext{
${ }^{5}$ More on the concatenation of the democratization of culture and governmentality, cf. Czyżewski 2018.
} 
institutional centralization, and, last but not least, the "imperialism of its 'truth"' that allowed Christianity to gain enormous influence in Europe in the early $4^{\text {th }}$ century $\mathrm{AD}$, ousting "pagan" forms of belief. The current gradual ebb away from Christianity, and from Catholicism in particular, certainly stems from numerous causes, among which we must not ignore those related to the growing resentment towards a situation where the patterns of religiousness, or-broadly speaking-spirituality, are regulated by means of regimes of truth.

\section{Conclusion}

Finally, I would like to return to my initial remarks and offer a general hypothesis concerning the interdependence of transitions in the field of knowledge and in the field of power relations: contemporary changes in the field of knowledge (in particular, post-truth, bullshit, and the destruction of attention) interact with numerous manifestations of governmentality, especially with the mechanisms of psychopower and regimes of post-truth. Regimes of truth, in turn, were not to be attributed to all social organizations, but they would rather be connected solely with sovereign and disciplinary power.

It should be added that such a hypothesis would stand in direct contradiction with key assumptions drawn by Foucault, which claimed the nonlinear character of social processes and the discontinuity of social reality (and, therefore, a lack of regular interaction between various fields of social life). Moreover, this hypothesis should be granted a limited range of validity by acknowledging the existence of communities and sectors of social life that are excluded from the field of "government through freedom." Most importantly, this hypothesis would also contradict the regularity proclaimed by Foucault (2014:7) with- out any exception that "there is no exercise of power without something like an alethurgy," where what Foucault understands by alethurgy is "the manifestation of truth as the set of possible verbal or non-verbal procedures by which one brings to light what is laid down as true." However, as I was trying to present, there is governmentality without truth.

What one may find perplexing is the consistency, if not obstinacy, which made Foucault cling to his-as I have striven to prove-wrong belief about the omnipresent relationship between knowledge and power. The explanation for this peculiar extrapolation can be found in post-Foucauldian studies. Namely, some of the latest publications (e.g., Lazreg 2017) criticize the Eurocentrism of his philosophy in reference to cultural otherness. The earliest re-evaluation of Foucault's oeuvre, which points to the lack of reflection on the possible impact of his own cultural identity (a white European man with an upper-class background) on the way he thinks about the world, can be seen in the "unorthodox" variant of a postcolonial theory proposed by Gayatri Spivak (1988). Perhaps, Foucault was so preoccupied with his own confrontation with the enlightenment mainstream of European culture that he never noticed the doxa shared by both sides. Admittedly, he did uncompromisingly contest the existing regimes of truth, and stressed that "nothing is more dangerous than a political system that claims to lay down the truth". On the other hand, however, he was convinced that "nothing is more inconsistent than a political regime that is indifferent to truth" (Foucault 1988:267). In his works on governmentality, he acutely emphasized the connection between this type of power relation and concern for security, showing a particularly keen interest in the avoidance of "case, risk, danger, and crisis" (Foucault 2007). Presumably, the blind spot of this apt diagnosis was the fact that he had missed the tendency for governmentality without truth. 


\section{References}

Boltanski, Luc and Ève Chiapello. 2005. The New Spirit of Capitalism. Translated by Gregory Elliott. London: Verso.

Bröckling, Ulrich. 2007. Das unternehmerische Selbst. Soziologie einer Subjektivierungsform [The Entrepreneurial Self]. Frankfurt am Main: Suhrkamp.

Bröckling, Ulrich, Susanne Krasmann, and Thomas Lemke. 2000. Gouvernementalität der Gegenwart. Studien zur Ökonomisierung des Sozialen [Governmentality of the Present. Studies on the Economization of the Social]. Frankfurt am Main: Suhrkamp.

Bröckling, Ulrich, Susanne Krasmann, and Thomas Lemke. 2011. “From Foucault's Lectures at the Collège de France to Studies of Governmentality: An Introduction." Pp. 1-33 in Governmentality: Current Issues and Future Challenges, edited by U. Bröckling, S. Krasmann, and Th. Lemke. New York: Routledge.

Czyżewski, Marek. 2013a. “W kręgu społecznej pedagogii [Amidst Social Pedagogy]." Societas/Communitas 2(16):43-73.

Czyżewski, Marek. 2013b. "Socjologia interpretatywna i metoda biograficzna: przemiana funkcji, antyesencjalistyczne wątpliwości oraz sprawa krytyki [Interpretive Sociology and Biographical Method: Change of Function, Anti-Essentialist Reservations, and the Problem of Critique]." Przeglad Socjologii Jakościowej 9(4):14-27.

Czyżewski, Marek. 2018. "A Brief Outline of Issues Related to the Democratisation of Culture: A Contemporary Perspective." Societas/Communitas 2-3(26-3):43-60.

Czyżewski, Marek. 2019. "Pitfalls of Participatory Approaches." Pp. 359-368 in Participatory Social Work: Research, Practice, Education, edited by M. Granosik et al. Lodz: Wydawnictwo Uniwersytetu Łódzkiego; Cracow: Jagiellonian University Press.

Dean, Mitchell. 2010. Governmentality. Power and Rule in Modern Society. London: Sage.

Deleuze, Gilles. 1995. "Postscript on the Societies of Control." Pp. 177-182 in idem, Negotiations, 1972-1990. Translated by Martin Joughin. New York: Columbia University Press.

Foucault, Michel. 1977. "The Political Function of the Intellectual." Translated by Colin Gordon. Radical Philosophy 12:12-14.
Foucault, Michel. 1980a. "The Confession of the Flesh.” Translated by Colin Gordon. Pp. 194-228 in idem, Power/Knowledge: Selected Interviews and Other Writings 1972-1977, edited by C. Gordon. New York: Pantheon Books.

Foucault, Michel. 1980b. "Truth and Power." Translated by Colin Gordon. Pp. 109-133 in idem, Power/Knowledge: Selected Interviews and Other Writings 1972-1977, edited by C. Gordon. New York: Pantheon Books.

Foucault, Michel. 1982. “The Subject and Power.” Pp. 208-226 in Michel Foucault: Beyond Structuralism and Hermeneutics, edited by H. Dreyfus and P. Rabinow. Chicago: University of Chicago Press.

Foucault, Michel. 1988. “The Concern for Truth.” Pp. 255-267 in idem, Politics, Philosophy, Culture. Interviews and Other Writings 1977-1984, edited by L. D. Kritzman. Translated by Alan Sheridan et al. London: Routledge.

Foucault, Michel. 1993. "About the Beginning of the Hermeneutics of the Self: Lectures at Dartmouth College, 1980." Political Theory 21(2):198-227.

Foucault, Michel. 2005. The Hermeneutics of the Subject. Lectures at the Collège de France 1981-1982. Translated by Graham Burchell. Basingstoke: Palgrave Macmillan.

Foucault, Michel. 2007. Security, Territory, Population: Lectures at the Collège de France, 1977-78. Translated by Graham Burchell. Basingstoke: Palgrave Macmillan.

Foucault, Michel. 2008. The Birth of Biopolitics: Lectures at the Collège de France, 1978-79. Translated by Graham Burchell. Basingstoke: Palgrave Macmillan.

Foucault, Michel. 2010. The Government of Self and Others. Lectures at the Collège de France 1982-1983. Translated by Graham Burchell. Basingstoke: Palgrave Macmillan.

Foucault, Michel. 2011. The Courage of Truth. The Government of Self and Others II: Lectures at the Collège de France 1983-1984. Translated by Graham Burchell. Basingstoke: Palgrave Macmillan.

Foucault, Michel. 2014. On the Government of the Living: Lectures at the Collège de France, 1979-1980. Translated by Graham Burchell. Basingstoke: Palgrave Macmillan. 
Foucault, Michel. 2017. Subjectivity and Truth. Lectures at the Collège de France 1980-1981. Translated by Graham Burchell. Basingstoke: Palgrave Macmillan.

Frankfurt, Harry G. 2005. On Bullshit. Princeton: Princeton University Press.

Giddens, Anthony. 1984. The Constitution of Society. Outline of the Theory of Structuration. Cambridge: Polity.

Giddens, Anthony. 1991. Modernity and Self-Identity. Self and Society in the Late Modern Age. Cambridge: Polity.

Harsin, Jason. 2015. "Regimes of Posttruth, Postpolitics, and Attention Economies." Communication, Culture \& Critique 8:327-333.

Höhne, Thomas. 2003. Pädagogik der Wissensgesellschaft [Pedagogy of the Knowledge Society]. Bielefeld: transcript.

Judt, Tony and Timothy Snyder. 2012. Thinking the Twentieth Century. New York: Penguin Press.

Lazreg, Marnia. 2017. Foucault's Orient. The Conundrum of Cultural Difference, from Tunisia to Japan. New York: Berghahn.

Lemke, Thomas. 1997. Eine Kritik der politischen Vernunft. Foucaults Analyse der modernen Gouvernementalität [A Critique of Political Reason. Foucault's Analysis of Modern Governmentality]. Hamburg: Argument.

Lukacs, Martin. 2017. “Neoliberalism Has Conned Us into Fighting Climate Change as Individuals." The Guardian, International Edition, July 17, 2017. Retrieved July 15, 2019 (https://www. theguardian.com/environment/true-north/2017/jul/17/neoliberalism-has-conned-us-into-fighting-climate-change-as-individuals).

Mannheim, Karl. 1952. "The Problem of a Sociology of Knowledge." Pp. 134-190 in idem, Essays on the Sociology of Knowledge. Translated by Paul Kecskemeti. New York: Oxford University Press.

Masschelein, Jan et al. 2006. The Learning Society from the Perspective of Governmentality. Oxford: Blackwell.
Miller, Peter and Nikolas Rose. 2008. Governing the Present. Administering Economic, Social and Personal Life. Cambridge: Polity.

Montaigne, Michel de. 1993. The Complete Essays. Translated by Michael Andrew Screech. London: Penguin Books.

Nealon, Jeffrey T. 2008. Foucault beyond Foucault. Power and Its Intensifications since 1984. Stanford: Stanford University Press.

Rose, Nikolas. 1996. Inventing Our Selves. Psychology, Power, and Personhood. Cambridge: Cambridge University Press.

Rose, Nikolas. 2004. Powers of Freedom: Reframing Political Thought. Cambridge: Cambridge University Press.

Sennelart, Michel. 2014. "Course Context." Pp. 326-356 in Michel Foucault, On the Government of the Living: Lectures at the Collège de France, 1979-1980. Translated by Graham Burchell. Basingstoke: Palgrave Macmillan.

Simons, Maarten and Jan Masschelein. 2008. “The Governmentalization of Learning and the Assemblage of a Learning Apparatus." Educational Theory 4:391-415.

Spivak, Gayatri Chakravorty. 1988. “Can the Subaltern Speak?" Pp. 271-313 in Marxism and the Interpretation of Culture, edited by C. Nelson and L. Grossberg. Urbana, Chicago: University of Illinois Press.

Stiegler, Bernard. 2010. Taking Care of Youth and the Generations. Translated by Stephen Barker. Stanford: Stanford University Press.

Veyne, Paul. 2010. When Our World Became Christian, 312-394. Translated by Janet Lloyd. Cambridge: Polity.

Williams, Bernard. 2002. Truth and Truthfulness: An Essay in Genealogy. Princeton: Princeton University Press.

Zaner, Richard A. 1973. "Solitude and Sociality. The Critical Foundations of the Social Sciences." Pp. 25-43 in Phenomenological Sociology: Issues and Applications, edited by G. Psathas. New York: John Wiley and Sons.

\section{Citation}

Czyżewski, Marek. 2021. "Governmentality without Truth: An Essay on the Role of Foucauldian Thinking in a Post-Truth Society." Qualitative Sociology Review 17(1):40-59. Retrieved Month, Year (http://www.qualitativesociologyreview.org/ENG/archive_eng.php). DOI: http://dx.doi.org/10.18778/1733-8077.17.1.4 